\title{
Casablanca 1907: Diario de campaña de un soldado gaditano
}

\author{
Introducción histórica y notas: \\ MANUEL BARAJA MONTAÑ̃ \\ Transcripción: \\ ANTONIO DE GRACIA MAINE
}

\section{INTRODUCCION HISTORICA}

El gran polo de la proyección exterior española tras el 98 fue la empresa africana como pieza de recambio con la que compensar la "merma de prestigio" y que se iba a convertir en una de las mayores fuentes de conflictos interiores.

A comienzos de siglo el problema de Marruecos adquiere una amplitud internacional, pues el estado de anarquía en que se encontraba el país era un constante peligro para las potencias que tenían intereses o posiciones en el norte de Africa. El país tan es así que estaba dividido en dos tipos de territorios: Blad-el-majzen (controlado por la autoridad del sultán) y Blad-el-Siba o zonas controladas por autoridades locales prácticamente autónomas y aún independientes.

La cercanía de Europa, las condiciones políticas del país y el espíritu de la época de acrecentar las colonias, hacían inevitable que el Imperio Xerifiano fuera a caer irremisiblemente en el área de influencia de las potencias europeas; y en este contexto España no podía permanecer al margen.

En 1902 comenzó la acción española entablando conversaciones con Francia, que de haber fructificado, habría dejado bajo control español la mayor parte del territorio marroquí, pero los políticos españoles no mostraron entonces gran interés ... o quizás el gobierno Silvela no quiso en aquel momento cargar con la responsabilidad de desagradar al Reino Unido. 
En 1904 se reactiva el tema en función de la penetración alemana en el territorio, que culminaría en la llamada crisis de Tanger cuando el kaiser Guillermo II desembarcó en aquella ciudad en marzo de 1905. La tensión internacional desembocaría en la Conferencia de Algeciras de 1906 que significó para España una gravísima carga al compartir con Francia (que se reservaría la mejor y más lucida parte) el mandato de organizar y sostener por espacio de cinco años la policía que habría de garantizar el orden y proteger al sultán. Comenzaba una intervención militar que prácticamente no cesaría en quince años con el consiguiente desgaste en hombres y recursos.

En 1907 se constituyó la compañía de las Minas del Riff como resultado de la política de penetración pacífica que habían iniciado los Centros Comerciales (1); y más tarde las tropas españolas ocupan la Restinga, lo que puede ser considerado como el primer acto de penetración española en Africa. Esta maniobra militar vino facilitada por la existencia en la región de Melilla de un jefe político local, apodado El Roghi, que dominando toda la región alrededor de Taza en el noreste, llegó a ser un verdadero pretendiente al sultanato marroquí y que no tuvo inconveniente en hacer concesiones mineras a los españoles $\mathrm{e}$ incluso permitir la construcción de una línea ferroviaria.

Ese mismo año, como resultado de los atentados de los marroquíes contra los europeos, especialmente contra franceses (Dr. Mauchamps), hubo ya una clara intervención armada que culminó en el desembarco franco-español de Dar-el Beida (Casablanca); comenzaba la llamada politica de tambor batiente. Los alemanes protestaron por lo que consideraban una violación del Acta de Algeciras y desde entonces menudearon los incidentes. La deposición del sultán Abd-el-Aziz por su hermano Muley Hafid acrecentó el estado de anarquía endémico en el país, con lo cual la Residencia General francesa en Rabat y la Alta Comisaría española en Tetuán tenían una ardua tarea por delante.

(1) Los Centros Comerciales tienen sus orígenes a fines de 1904, y nacen para "cooperar al desarrollo de nuestra influencia comercial en Marruecos". Para ello propugnan una serie de medidas como fomentar los estudios arábigos en la Península; instalar sucursales del Banco de España en Melilla, Ceuta y Tánger; tender cables submarinos de costa a costa y sobre todo modificar el artículo 229 del reglamento de Aduanas, por lo cual se consideraban productos extranjeros todos aquellos que hubiesen hecho escala en el litoral marroquí.

La organización y objetivos de estos Centros están respaldados por la plana mayor del Partido Liberal (Moret, Romanones) e incluso por los más insignes representantes del reformismo democrático ( $G$. de Azcárate, Portela Valladares). Ellos representan la caja de resonancia pública y parlamentaria de mayor calibre de estas sociedades. 
El gobernador de Melilla, general Marina(2), pidió refuerzos y la necesidad de llamar a filas a los reservistas alentaría el espíritu revolucionario. La guerra de Marruecos se iba a convertir en una pesadilla para los políticos y para un ejercito que una y otra vez demostró su falta de preparación (3) a despecho de muchos episodios de valor personal.

Pero la cuestión marroquí no sólo se iba a convertir en un motivo de enfrentamiento político, con la izquierda extradinástica siempre opuesta a la aventura (4), sino de graves conflictos sociales como desencadenamiento de la Semana Trágica que traería la caída de Maura.

\section{BREVE BIOGRAFIA DEL AUTOR}

José Cambiazo Botana nace en Cádiz en 1884 y como norma de aquellos tiempos, a los 7 años, inicia su asistencia a una Escuela de enseñanza primaria de su barrio, destacando por su aprovechamiento y facilidad para el dibujo y caligrafía. A los 14 años entra como aprendiz en un taller de cerrajería de la localidad y consigue al poco tiempo la categoría de oficial cerrajero.

Cuando cumple los 20 años, le llega la llamada para el servicio militar obligatorio, siendo destinado a Africa, incorporándose a un Regimiento de Infantería de guarnición en la plaza de Ceuta. Asciende a cabo y sargento y es licenciado a los tres años de servicio.

Ya de nuevo en su hogar, se reintegra a su profesión de cerrajero mecánico en el mismo taller, cesando en 1918 para ocupar un puesto de broncista en el dique de Matagorda hasta 1922.

Durante el período 1922/1933 se establece con taller propio en su ciudad natal, compaginando este quehacer, desde 1930, con las clases en la Escuela de Artes y Oficios de Cádiz, de la que había sido nombrado profesor. Muere en esta misma ciudad en 1933.

(2) José Marina y Vega participó en la guerra de Cuba, fue gobernador militar de Valencia y Melilla y, en 1909, ascendido a teniente general, fue nombrado comandante en jefe del ejército de operaciones en Marruecos. En 1917 fue ministro de la Guerra con el gobierno de Dato.

(3) No vamos a entrar aquí en cuestionar si la empresa neocolonial en Marruecos fue conveniente o no, pero lo que es evidente es que los políticos de la Restauración tomaron conciencia del problema militar y permitieron que la inquieta e inquietante sociedad militar "gastase la pólvora espiritual acumulada".

(4) Para la oposición republicano-socialista la presencia española en Marruécos era movida por los intereses de unos happy few de la clase gobernante adinerada. Tesis que defienden historiadores como Tuñón de Lara y Morales Lezcano, y que sin embargo otros como André Bachoud lo relativizan como factor decisivo. 
Es de señalar principalmente la cualidad de autodidacta que se refleja constantemente en esta persona, que en 1922 termina de escribir su obra "Prácticas de cerrajeria", que no llega a publicar.

\section{CAMPAÑA EN CASABLANCA DE LAS TROPAS ESPAÑOLAS PROCEDENTES DE CEUTA. DETALLES MAS INTERESANTES ATRAVESADOS POR LAS MISMAS EN ELLA DURANTE EL TIEMPO DE SU ESTANCIA (5)}

El día 12 del mes de Agosto de 1907 fue fondeado en el puerto de Ceuta el trasatlántico "Ciudad de Cádiz", y al efecto se fue abordando a dicho buque el material de guerra y provisiones correspondientes para más de 400 hombres y 150 caballos que habían de ser transportados por el mismo hacia Casablanca; ciudad que en las actuales fechas se hallaba acometida por el efectuoso salvajismo de los moros. El vapor mencionado fondeó a las 11 del citado día, y a las 6 de la tarde, una vez terminado el trasbordo del mencionado combustible se dio principio al embarque de nuestra tropa; la que se efectuó a presencia del general de la guarnición y Subinspector de la Plaza en medio de atronadores vivas de los hijos de la patria (6) que fortalecían más y más al ánimo de nuestros soldados ansiosos de buscar una pronta venganza. Terminó el embarque de nuestros soldados a las 10 de la noche del citado día; levó ancla nuestro buque y emprendió su salida entre la oscuridad de la noche, avanzando, con su majestuosa marcha, hacia el lugar en que se encontraban un puñado de hijos de la patria esperando a los que habían de ser sus salvadores.

(5) La versión del texto "Recuerdos de Casablanca" ha procurado mantener al máximo la originalidad inicial del mismo. Sólo se han corregido algunos aspectos de las peculiaridades ortográficas que se producen en un escrito primerizo y por tanto algo descuidado. En la puntuación y en los períodos sintácticos se observan detalles discutibles en cualquier normativa, pero su total modificación conllevaría alejarse del estilo del autor. Pueden encontrarse, en este sentido, elementos contradictorios, pero hemos considerado, una vez hecha la aclaración, que el lector sea juez en estas cuestiones.

(6) La intervención militar española en el problema de Marruecos no acababa sino de empezar y todavía las despedidas a los soldados son alegres. Muy poco después la guerra se haría impopularísima, en las Cortes diversos diputados se opondrán a la concesión de créditos y en la calle bullirá el descontento... el antimilitarismo ha calado en todas las clases sociales. 
La travesía fue alegre y resplandeciente para nuestros soldados pues se disfrutaba de un tiempo bondadoso. En las 18 horas que duró todo fue alegría y contento. Los soldados en las horas de las comidas lo hacían en grupos de a 10 y 12 y entre ellos se oían de continuo el gratísimo clamoreo producido por los chistes y ocurrencias atrevidas al fin que se les conducía.

A las 4 de la tarde del día 13 del actuante mes se divisan los hermosos buques Río de la Plata, D. Alvaro de Bazán, españoles; y el Galileo, Glorie y Condé franceses; en este momento se empezaba a dar la comida a nuestros soldados al par que el Galileo pasaba por la proa de nuestro trasatlántico, tributándonos sus tripulantes muchos vivas y recorriendo después por los alrededores de la población, bombardea incesantemente a los kabileños (7) que atacaban con ímpetu las avanzadas francesas, siendo rechazados de éstas con considerables pérdidas. Momentos después y una vez terminada la comida se procedió al desembarco de nuestra tropa, siendo efectuada la de infantería con vertiginosa rapidez producida por el ánimo de nuestros soldados que se disputaban los unos a los otros en ser los primeros en pisar tierra. La caballería no pudo hacerlo hasta el siguiente día a causa de ser de noche. Al día siguiente a las 5 de la mañana se empezaron los trabajos de desembarco para ella no sin tener que lamentar la caída de una caballo que zafándose del aparejo que lo embragaba fue al agua el noble animal, nadando dos espacios iguales a la longuitud del barco. Una de las lanchas vaporas de nuestro crucero $D$. Alvaro de Bazán, que se encontraba prestando el servicio de facilitar nuestros desembarcos, siguió al fogoso animalito que se esforzaba por su vida, siendo alcanzado y amarrada la cabeza a la mura (8), sujeta por la lazada práctica de nuestros marinos. Siendo remolcado hasta el escabrosísimo muelle, inútil para toda clase de desembarco, en él que pisando el duro suelo se restableció prontamente y fue a buscar la unión con sus compañeros que no con poco trabajo volvieron a pisar la tierra; viéndose obligados los autores del desembarco a arrojar los caballos al

(7) El autor hace referencia a los componentes de las kabilas insumisas. Las kabilas o tribus sometidas podían ser Guich y Naiba según formasen el ejército permanente o abonasen un impuesto respectivamente. Ambas estaban regidas por un gobernador o kaid y tenían multitud de funcionarios. Por el contrario las kabilas insumisas, de raíz bereber, carecían de esa organización y la soberanía la ejercía la Yemáa o asamblea de hombres capaces. Contra éstas fue con quienes tuvieron que luchar franceses y españoles.

(8) Por una aféresis se refiere a la amura o parte de los costados del buque donde éste se estrecha para formar la proa. 
agua y éstos, después, pausadamente, se iban incorporando con sus compañeros.

Volvamos a lo anterior, o sea, a nuestra infantería que la dejamos para seguir con el desembarco de la caballería. Una vez en tierra se comenzó la marcha hacia nuestro Consulado en que fue acogida con muchísimo entusiasmo, encontrándose guarnecido por 24 marinos del D. Alvaro de Bazán enterando éstos a los recién llegados infantes los detalles más culminantes que atravesaron para llegar al previsto nido en que albergaban los subditos españoles; el relato fue muy extensísimo y en él se veía una vez más el heroísmo de nuestros marinos que como siempre habían sabido colocar a muy buena altura nuestro pabellón derramando su preciosa sangre: un cabo de cañón, muerto, y tres soldados marinos derramaron su sangre pasando a aumentar el número de heroínos en nuestra historia que tanto nos llena de gloria.

Guarnecimos el Consulado con nuestras tropas y nuestros marinos fueron reembarcados; después nuestras tropas recorrieron la población en concepto de paseo y el aspecto de la misma era imponente, aterrador por el estado de desolación en que se encontraba. Muchísimas casas destruidas por el efecto de los proyectiles de nuestros barcos españoles y franceses; barrios enteros destruidos por los incendios producidos por los moros. De éstos se veían muchos cadáveres que pagaron con su vida sus hechos inhumanos; la mayor parte de las casas saqueadas por ellos mismos.

El hedor que despedía el que en estado normal había sido un hermoso pueblo, lleno de industria y comercio, era insoportable: nubes de moscas cubrían los cadáveres y las inmundicias de que estaban llenas las calles, algunas de ellas se hallaban cubiertas también de cebadas cerca de una vara de espesor; haciendo todo ello imposible el paso a nuestros soldados, con muchísima pausa, aterrados por los desconsoladores cuadros que se presentaban a su vista. Muchos paisanos nos interrumpían también para relatarnos sus hechos contra los terribles kabileños que habían cometido toda clase de inicuos atropellos, violando mujeres y robándolas de su hogar para no volver a recuperarlas más. A las 8 y media de la noche se oyó el toque de Escuadra por nuestro corneta de la guardia de nuestro Consulado, acudiendo todos con rapidez a su nuevo alojamiento: 19 minutos después el de Compañia y poco después el de Retreta que fue la señal de que nuestra tropa quedaba albergada en su nuevo hogar, dispuesta siempre a las primeras insinuaciones de sus jefes.

Varios tiros se oyeron en el transcurso de la noche y que fueron contestados por las guardias francesas, que muy repartidas se halla- 
ban, nos hicieron comprender que habíamos de observar muy estrecha vigilancia por encontrarse ocultos entre las escabrosidades (9), que presentaba la población, algunos sueltos enemigos que hasta la fecha en que nos ocupamos no habían podido ser arrojados. Varias noches más se produjeron estos sucesos, en las cuales tocó la suerte a nuestros soldados centinelas la captura de dos moros comprendiéndose como espías; los cuales fueron entregados al general francés Drudé para la resolución que estimara conveniente. Teniendo entendido nosotros según versiones francesas, que dichos dos espías así como muchos más que fueron capturados por los franceses, barrieron y quitaron las inmundicias en unas cuantas calles; haciéndose después cada uno su sepultura personalmente obligados por los franceses, los que después les fusilaban (10). Caro parece que pagaran según el anterior relato, pero más se merecían pues ellos y los demás de su raza al cristiano que caía en sus criminales manos le mutilaban horriblemente, le cortaban las manos, los pies y después de hacer otras tantas herejías que nos impresionarían grandemente al relatarlas, terminaban su vida cortándole la cabeza y llevándola clavada en un palo como trofeo.

$\mathrm{Al}$ amanecer del día $18 \mathrm{del}$ mes que encabeza estos recuerdos el continuo bombardeo de los barcos franceses y españoles nos avisaba que el enemigo se encontraba muy cerca; las avanzadas francesas se defendían inutilmente dado el considerable número e impetuoso avance de los moros.

Rápidamente se movilizaron las tropas francesas y seguidamente rompieron contra el enemigo en vivo fuego de fusilería.

Las avanzadas se replegaban ordenadamente acosadas por centenares de moros. Los cañones funcionaron con destreza para evitar que fueran atacadas. Miles de jinetes caían sobre los franceses con valentía imponderable amenazando romper sus líneas y llegar a la ciudad. Se reunían en grandes grupos y al galope desenfrenado de los caballos

(9) Los españoles turvieron que moverse por un medio totalmente desconocido para ellos, y la orografía era tan complicada que pudo decirse que a España le había tocado en suerte "el hueso de la Yébala y la espina del Riff". Así, el enemigo, usando la táctica del guerrillero trajo en jaque a las tropas españolas, que no sabían como contrarrestar esa forma de pelear.

(10) Es de resaltar que nuestro protagonista insiste en varios apartados de su Diario cómo los franceses de una manera sistemática fusilaban a sus prisioneros, dejándolos que se pudriesen al sol o en el mejor de los casos enterrándolos en una fosa común. Por el contrario, cuando se refiere a las tropas españolas, éstas no pasan de aterrar, con diferentes sistemas, a los moros detenidos para luego entregarlos siempre, según el autor, a la autoridad competente. 
y sin dejar de cesar el fuego caían sobre los franceses que los esperaban a pie firme. Las bombas de melinita (11) los barrían materialmente, haciendo enormes claros en los grupos. Aquellos que conseguían llegar hasta las filas francesas caían acribillados a balazos o a ballonetazos pues en varias ocasiones se batieron cuerpo a cuerpo. Millares de jinetes realizaron un movimiento envolvente combinado intentando rodear las posiciones francesas que estuvieron en momentos seriamente amenazadas.

La artillería se esforzaba inutilmente en contener a los kabileños.

Estos se aglomeraban sobre el flanco izquierdo realizando los movimientos con rapidez vertiginosa y despreciando los estragos de las bombas de melinita que materialmente los aniquilaba. Los supervivientes se levantaban de entre los montones de muertos y heridos y continuaban combatiendo con igual denuedo (12).

El general Drudé recorría el campo de batalla dictando órdenes. Viendo la peligrosa maniobra de los moros mandó a noventa Spahis de caballería (13) a que contuvieran el ataque. A galope frenético se lanzaron sobre la caballería rebelde, luchando cuerpo a cuerpo largo rato.

Viendo que a pesar de sus esfuerzos los spahis se veían copados, el general Drudé envió dos Compañías de Cazadores que desplegados en guerrilla atacaron vigorosamente a la bayoneta apoyados por un escuadrón de Cazadores de Africa que les cubrió la retaguardia.

La acometividad de los infantes sorprendió a los kabileños obligándolos a abandonar a los spahis que sólo tenían por retirada el mar. Los moros se dividieron en grupos, aprovechando esta oportunidad los spahis para reponerse y atacar de nuevo. Dos spahis quedaron muertos y tres heridos, también quedaron muertos 10 caballos.

Mientras continuaba el fuego de los buques, los franceses atrincherados rechazaban a los moros que surgían de todas partes. A media tarde un grupo enorme de kabileños formados como las tropas (españolas) europeas, avanzó en columna de fondo ordenadamente, hacien-

(11) La melanita es un explosivo constituido esencialmente por ácido pícrico, que empezó utilizándose como colorante para terminar mezclado con diversas sustancias como carga de diversas municiones explosivas (obuses, granadas, etc.).

(12) Los bereberes que se enfrentaron a los españoles dieron pruebas de su valor en repetidas ocasiones, como reflejo de su indudable vocación guerrera. No olvidemos que José Cambiazo y sus compañeros tenían enfrente a la tribu de Beni Urriaguel, máxima representante de la pureza racial y de donde, no por casualidad, saldría Abd-el-Krim.

(13) Los spabis fueron los componentes de la aguerrida caballería turca. Por afinidad el autor utiliza esa terminología en vez de "jinetes". 
do fuego por descargas, llegando a medio kilómetro del Campamento. Las mortíferas descargas de la fusilería les hicieron huir, abandonando muchísimos muertos y heridos.

Desde que comenzó la acción los cruceros Gloire, Galileo y el cañonero español $D$. Alvaro de Bazán, arrojaron incesantemente sobre el campo moro bombas de melinita y de metralla. El bombardeo repercutiría en un fragor horrísono en las montañas.

Temblaba la tierra, ardían los matorrales, volaban las peñas hechas pedazos, unos lejanos aduares (14) eran arrasados y grandes grupos de moros volaban enteros. Se calcula que al medio día habría más de 500 moros fuera de combate.

Al oirse los primeros disparos el Sr. Santa Olalla, Jefe de las tropas españolas, envió al general Drudé un mensajero ofreciéndole el mando de ellas. El general Drudé agradeciéndolo, lo rehusó por estimar que contaba con fuerzas suficientes para rechazar el ataque.

Los oficiales y soldados españoles, disgustados por la inacción en que se encontraban, rogaron al Jefe que se les permitiera salir al campo. Accedió a ello el Sr. Santa Olalla marchando primero la caballería al galope y luego la infantería. Las tropas españolas llegaron a la línea de combate en el transcurso, no sin ponerse antes de acuerdo con el Comandante del $D$. Alvaro de Bazán para que protegiera sus movimientos.

$\mathrm{Al}$ aparecer nuestras tropas, en el trozo que se le tenía asignado para sus operaciones, vieron las primeras lomas que forman el perímetro coronadas sus alturas de grupos de moros que apercibidos de nuestra pequeña columna y nuestro cañonero $D$. Alvaro de Bazán, que había avanzado hacia el flanco derecho designado para nuestras operaciones, huyeron despavoridos, abandonando la línea de combate.

Las tropas españolas continuaron en el campo hasta las seis de la tarde, hora hasta la cual no se había vuelto a ver la presencia enemiga, marchando después hacia nuestro Consulado.

El día 22 volvieron a salir las tropas españolas reconociendo 'éstas, en el campo de sus operaciones, unas cuantas casas como medidas de precauciones.

Al reconocer una de las más lejanas, se divisaron unas parejas marroquíes que como en concepto de espías recorrían por las veredas que atravesaban las lomas. Sonaron varios disparos de fusilerías en

(14) Los aduares eran pequeños campamentos formados por tiendas, chozas o cabañas, habitados por bereberes. 
las lejanías y nuestra avanzada contestó con fuego graneado, fuego que sirvió para perder de vista la presencia de nuestros enemigos que se perdieron entre las escabrosidades de la montaña (15).

Varias salidas más efectuaron nuestras tropas en las cuales se sostuvo con los espías enemigos algunos disparos; recorriendo después, al regreso de nuestras tropas por el exterior de la población y presentándose siempre a nuestra vista un sin número de casas arruinadas e incendiadas; aquí y allá cadáveres en completo estado de descomposición; un sin número también de fosas de obra de los franceses para enterrar a los moros que diariamente fusilaban (16).

Por todas partes y entre las ruinas de las casas se cruzaban multitud de perros y gatos rabiosos por el hambre que aullaban desaforadamente a causa de la pérdida de sus amos que habían abandonado sus moradas aterrados por los estragos de los moros que se repetían sin cesar, quedando los animalitos solos entre las ruinas, merced a las balas, palos o piedras de los unos y otros contendientes. Muchos de estos animalitos eran muertos por los franceses por encontrarse en estado de hidrofobia que el hambre les producía.

El día 30 ordenaron que nuestras tropas fueran acampadas a la inmediación del Santuario Sidi-Bellot, el cual se halla situado en el flanco derecho de la zona de combate. En este día se efectuaron los trabajos para el establecimiento del Campamento; en una espaciosa huerta que se hallaba en el lugar que ya se tiene mencionado.

Trabajo costó a nuestros soldados el edificar su nueva morada; pues estuvieron todo el mencionado día arrancando los ricos sembrados de que estaba cubierto el que había de ser su suelo, terminando este trabajo a las 5 de la tarde, hora designada para su comida, la que les aguardaba en el Consulado.

Al día siguiente salieron de la ciudad para quedar establecidos en lo sucesivo en su nueva morada.

Una vez en ella se dio principio a montar 18 tiendas de campaña, 4 más de construcción cuadrada para recreo, un Cuerpo de Guardia bastante amplio y otro caserón no mal construido para los sargentos que comprendían en las citadas fuerzas. Todos estos trabajos se efectuaron estableciendo con anterioridad una avanzada para protegerlos.

Dicha avanzada a las 12 del día 31, que es el que nos ocupa, cruzó sus balas con las de un grupo enemigo que tuvieron la osadía de acercarse, sin duda alguna, para espiar nuestros movimientos; pero la

(15) Cfr. nota $n^{0} 9$.

(16) Cfr. nota no 10 . 
certera puntería de nuestros soldados les hicieron huir desaforadamente registrándose algunas bajas; nuestros soldados ninguna.

$\mathrm{Al}$ anochecer del citado día, se estableció el servicio de la noche con dos oficiales, dos sargentos, 4 cabos y 60 soldados, de los cuales hacían la mitad de la referida fuerza el primer cuarto de la noche y la otra mitad el segundo. Al empezar el segundo nuestros centinelas divisaron algunos bultos que merodeaban nuestros contornos. Fueron avisados los cabos de guardia por los centinelas y por conducto regular llegó la noticia a nuestros primeros jefes quienes ordenaron que se tocara el pito (17), señal a la cual los imaginarias habían de llamar a los soldados que dormían en las tiendas de campaña y a otra segunda pitada habían de estar todos en el lugar designado para el caso de alarma, en el cual la primera compañía había de situarse en el costado derecho de la fortaleza, frente al enemigo, y la segunda en el izquierdo, dividiéndose las secciones ocupando cada una la tercera parte de su respectivo costado.

Una sola pitada bastó para que los soldados ocuparan el lugar designado para el combate no siendo preciso el aviso de las imaginarias; se ordenó que se rompiera un discreto fuego sobre los bultos que se aproximaban.

Unos cuantos disparos bastaron para que el enemigo desapareciera, en vista de lo cual se deducía que el enemigo se ilusionaba de podernos dar una sorpresa, huyendo despavorido de su inútil y arriesgada empresa.

$\mathrm{Al}$ amanecer se divisó por la altura de las primeras lomas algunos grupos de moros de a pie y a caballo que fueron dispersados instantaneamente por el mortífero fuego de nuestras dos ametralladoras que se hallaban establecidas en la cúspide de nuestra fortaleza. Establecida la tranquilidad se procedió a continuar en los trabajos de atrincheramiento.

Al día siguiente, a las tres de la tarde, una Sección de nuestra caballería se lanzó en las alturas de las lomas, quemando unas cuantas casas que servían de guarida a los moros durante la noche. Unos cuantos espías fueron dispersados de aquel lugar, yéndose a perder entre las escabrosidades de los montes. Varios reconocimientos análogos al anterior hizo nuestra caballería, en el transcurso de algunos días, sin tener que lamentar bajas en sus filas.

(17) Nó es usual utilizar este instrumento para dar órdenes, pero algunos oficiales lo usaban de forma aleatoria, a pesar de contar con cornetas entre sus subordinados como sabemos que es el caso de la guarnición que nos ocupa. 
De noche se hizo una estrechísima vigilancia por repetirse los merodeadores mencionados anteriormente, los cuales eran siempre dispersados y las noches de espesísima niebla se reforzaba el cordón de centinelas con 20 hombres más.

Hasta la fecha que nos ocupa parece ser como que, a nuestros soldados, le protegía la Providencia, pues siendo tan pocos, llegando al escaso número de 400 entre Infantería y Caballería, podían ser atacados por unos miles de moros de los que coroneaban la frontera por lo cual toda resistencia podría parecer inútil por parte de nuestras tropas; pero como ya se ha dicho, la Providencia, sin duda alguna, los protegía. Las tropas francesas que ascendían a más de 6.000 hombres, se veían de continuo agredidas por millares de moros que las atacaban vigorosamente costándole no poco trabajo, a dicha tropa francesa, que era también apoyada por la escuadra que fondeaba en el puerto, el rechazar el ataque de sus enemigos.

Los españoles se resignaban esperando algún día ser atacados análogamente; en lo cual no esperaban llevar mejor parte.

Al amanecer de cada día se hacía la descubierta por una Sección y uno de los citados días, antes de salir, se notó la presencia del enemigo que se aglomeraba entre unos cañaverales que se encontraban frente a nuestro Campamento. Se suspendió la salida de la Sección y se acudió al amparo de las ametralladoras, las cuales no tuvieron que hacerse repetir en su provechoso cometido; huyendo los moros a la desbandada desaforadamente dejando algunos muertos y heridos.

$\mathrm{Al}$ día siguiente se efectuó la descubierta protegida además por otra Sección de Caballería, la que se lanzó sin temor a las alturas de las lomas primeras y segundas, incendiando cuantas guaridas se encontraban a su paso de los enemigos (rebeldes) salvajes; incendiándoles también un depósito de paja y cebada al cual iban todos los días a horas determinadas los moros a sustentar a los caballos. En esta empresa como siempre el enemigo se quitó del alcance de nuestros fusiles.

Todos los días eran conducidos por una pareja de Caballería o por un cabo y cuatro soldados de infantería, sueltos moros con una bandera parlamentaria que se nos presentaban manifestando ser de los que los moros del campo obligaron por la fuerza llevándolos para que pelearan también en contra de los europeos.

En el transcurso de estos días se estableció la policía exterior española; componiéndose dicha policía de diez moros de los que prestaban su servicio a España en Ceuta, de donde procedían; siendo los 
jefes de la citada policía el Comandante Sr. Santa Olalla, el capitán Ovelo y además cuatro sargentos instructores (18).

Los citados moros policías, según instrucciones recibidas de sus jefes, apresaban y conducían de continuo, hacia nuestro Campamento, numerosos judíos y moros que aprovechando la ocasión de que el pueblo se encontraba desolado se dedicaban a robar en las ricas huertas que se hallaban abandonadas, uvas, higos, membrillos y otras mil frutas.

Estos judíos, nuestros oficiales antes de presentarlos al Jefe de la policía les daban unos sustos muy sensacionales en la forma siguiente (19): los cogían y a la viva fuerza los tendían en el suelo y hacían como que trazaban la medida para hacerle la sepultura, y luego, después, les daban picos y palas para que ellos mismos se las abrieran; estas operaciones los apuraban grandemente, se echaban a llorar como chiquillos, les besaban los pies, las manos, prometiendo no volver a robar más. Después, como muestras de algún perdón los forman a ayudar a nuestros soldados en los trabajos de atrincheramiento y poco rato después de haberse reído de la cobardía y temor de ellos les daban sueltas advirtiéndoles antes que, al volver a repetir la misma faena, no habría perdón para ellos.

El día 10 de septiembre después del toque de Diana, se prepararon nuestras tropas para hacer la descubierta que diariamente se efectuaba; en el expresado momento notaron los oficiales que mandaban dicha fuerza que el enemigo se encontraba guarecido en un cañaveral que distaba 1000 metros del Campamento. Se dispuso que las ametralladoras hicieran fuego. A los primeros disparos de éstas abandonaron el cañaveral, yendo a refugiarse entre las escabrosidades de las primeras lomas y entre las ruinas de las casas que días anteriores habían sido incendiadas por nuestra caballería. Se ordenó que una Sección de Caballería atacara por la derecha y la guerrilla por la izquierda, haciendo salir a los enemigos de sus guaridas y arrojarlos fuera de las lomas. Huían desaforadamente, no atreviéndose dar frente a nuestros soldados que los anonadaban, con su certera puntería, a pesar de la distancia a la que se encontraban.

(18) Nos encontramos ante un caso clarísimo de uno de los males que aquejó a la guerra de Marruecos: la macrocefálica oficialidad. Sería innecesario insistir en la desproporción en que se encontraron a lo largo de los años de campaña los soldados con respecto a sus oficiales, como eco de lo que ocurría a nivel nacional ( 80.000 soldados para 500 generales y 24.000 oficiales).

(19) Cfr. notas $\mathrm{n}^{\circ} 10$ y 16 . 
No contentos los moros con su inútil y arriesgada empresa, a la hora de la primera comida de nuestros soldados y aprovechando la espesísima niebla de que estaban cubiertas las lomas, atravesaron éstas sin ser vistos, llegando hasta 700 metros de nuestro Campamento, en número más considerable que el de la mañana. Un tiro dirigido hacia los soldados de Caballería, que se encontraban de avanzada a 300 metros del campamento, fue la expectación de que el enemigo trataba de nuevo sorprendernos. Quince minutos después un centinela del ángulo izquierdo del frente del Campamento nos avisaba con la detonación de su fusil y su potente voz de: ¡Cabo de guardia, que vienen los moros! Nuestros soldados que se hallaban formados para la distribución del rancho hubieron de trocar el plato por el mauser (20) y colocarse en el lugar que cada uno tenía asignado de antemano para la defensiva, al mismo tiempo las ametralladoras empezaron a regalarles sus ligeros confites que ellos empezaron a despreciar con la espalda, huyendo a la desbandada; algunos de los más atrevidos que trataron de despreciar los estragos de las balas pagaron con su vida tan inocente insolencia; quince minutos después no quedaba en el campo rastro del enemigo que se había llevado no pocas bajas.

Las tropas españolas no sufrieron desperfecto alguno, debiéndolo a sus buenos parapetos. Poco después quedó restablecida la tranquilidad distribuyéndose la comida que tan barbaramente había sido interrumpida.

El día 17 del actuante mes fue visitado nuestro Campamento, como ya se tenía anunciado con anterioridad, por el Ministro de Francia en Tanger monsieur Renault (21), acompañado del General Drudé, Jefe de las tropas francesas que operan en los campos de esta población. Al presentarse la comitiva le salió a su encuentro el Capitán Ayudante Sr. Avila. El escuadrón de caballería de Alfonso XII que se hallaba en el exterior del costado izquierdo del Campamento, dando frente a los altos personajes que se aproximaban y al enemigo, tributó a la expresada comitiva los honores de ordenanza; esto es: terciándoles las armas; demostrando la más exacta disciplina en sus movimien-

(20) Cfr. notas no 9 y 15 . Una vez más vemos como la táctica de los moros era el desconcierto, el cansancio entre los españoles, atacándoles en sus horas de descanso, comida, etc., para retirarse en breves minutos y repetir la acción cuantas veces hiciese falta.

(21) Aunque en el texto aparezca incorrectamente escrito es una clara referencia a $M$. Regnault, el mismo que el 30 de marzo de 1912 firmaría con Mulay-el Hafid un importante acuerdo. 
tos al par que los cornetas de dicho cuerpo batían la marcha que para este honor está ordenado.

En el interior del Campamento se encontraban las dos compañías en línea de columna dando frente al enemigo, así como los tiradores del Rif que ocupaban la izquierda de la mencionada fuerza. La presencia del funcionario y del General de la División francesa fue saludada también por la tropa de infantes con los honores de ordenanza, quedando los citados personajes satisfechísimos de la desenvoltura y disciplina de las tropas españolas, así como del estado de condiciones para sitio de guerra, fortificación y aseo del Campamento. Y en verdad que era digno de elogio, no obstante de encontrarse establecido el mencionado campamento en tierra de labor, que todo era tierra movediza y laborada; se encontraban los soldados españoles, sin exceptuar a ninguno, completamente limpios a pesar de vestir el traje de verano que es casi completamente blanco en la uniformidad española y usándolo en el mes que nos ocupamos por pertenecer dicho mes a la expresada estación.

El Campamento también era digno de elogiarlo pues se encontraba como ya se tiene dicho en perfecto estado de policía. Las casas de campaña habían sido completamente limpiadas del polvo colorado que era motivado por el referido suelo de labor; el interior de ellas también se encontraba perfectamente limpio, hallándose cubierto de paja de más de un pie de profundidad. Esta paja, para evitar el esparcimiento, se extendía en el suelo de las tiendas de campaña, pero encerrada entre dos aros o anillos que habían sido confeccionados de la forma siguiente: en derredor del extremo interior de las tiendas se habían clavado piquetes de madera y entre dichos piquetes se iban entrelazando cañas verdes recién cortadas de los cañaverales, que el día anterior había servido de guarida a los moros, y en el centro se formaba el otro anillo, dejando también con los referidos piquetes y cañas, una calle que permitía la salida y la entrada en las tiendas sin temor a pisar la paja que servía de lecho a los soldados españoles para evitarles las enfermedades que produce la humedad de la tierra (22).

Un pequeño jardín que poseía el campamento, en el interior próximo a la vanguardia, también se hallaba en perfecto estado de cuidado;

(22) La campaña puso de manifiesto que los servicios médicos eran pésimos, habiendo mejorado muy poco desde el desastre de Cuba. La sexta parte de los soldados pasaron por la lista de enfermos, y sabemos por ejemplo que en Monte Arruit, tan sólo a 30 kilómetros de Melilla, años más tarde hubo que amputar una pierna con navaja de afeitar. 
detrás del referido jardín, entre éste y las 18 tiendas de campaña estaban las tropas españolas en la formación antes dicha. El aspecto que presentaba el Campamento causó en sus visitantes satisfacción profunda; éstos fueron obsequiados después por el Comandante Sr. Santa Olalla, Jefe de las tropas españolas, en el mismo lugar con un espléndido refresco. En él se escucharon algunos vivas y brindis de los unos y los otros relativos a ambas nacionalidades. Al día siguiente con motivo de haber perecido un oficial y un sargento franceses ordenó el Comandante Sr. Santa Olalla un piquete compuesto de un oficial, dos sargentos, cuatro cabos y cincuenta soldados y la banda escasa de trompetas y tambores con que contaba nuestra también escasa fuerza para acompañar, en unión de los franceses, al acto de dar sepultura a los antedichos fallecidos.

En los días restantes del presente mes, a medida de su transcurso, se ha ido normalizando la tranquilidad, pues parece ser que con la derrota de las kabilas por los franceses sufridas en los días 10 y 11, la acometividad frustrada de dichas cabilas sobre nuestro Campamento el día 10 y otra nueva derrota del día 11 de los moros en su campamento "Jardet" por los franceses, y los rumores circulados del aproximamiento del Sultán con número considerable de fuerzas castigando a las kabilas rebeldes, les han llevado a entablar algunas proposiciones de paz lo que en esta fecha se considera inseguro. Todo ello mantiene a los referidos kabileños en una incertidumbre, la cual aprovechan las fuerzas de ocupación para reponerse y prepararse mejor en la línea de combate.

Dicha tranquilidad es aprovechada también por los moros pacíficos para presentarse a los campamentos españoles y franceses, corriendo el riesgo dichos moros de encontrarse con las balas de las kabilas enemigas que merodean de continuo y en escaso número, para no ser vistos, en busca de éstos más nobles que ellos consideran traidores.

El día 20 entre tres moras y cuatro moros que se presentaron venía uno de ellos herido por sus perseguidores, dejando otro muerto en el campo y logrando ellos burlar a fuerza de muchas fatigas la vigilancia de sus enemigos.

Entre estos mencionados y todos los presentados en el transcurso de este mes fueron puestos a disposición del Sr. Comandante Jefe de las fuerzas expedicionarias un total de 56 moros fugitivos. En los campamentos franceses también eran presentados en número muy considerable.

También fue apresado por nuestros centinelas un moro que pretendía pasar de la población al campo ocultándose de la vista de los centinelas de la fuerza de ocupación; fue presentado también a la vista 
de la misma autoridad. Nuestro Campamento fue invadido en los últimos días del mencionado mes por las lluvias; varias tiendas de campaña se derribaron a causa de ellas, pues como quiera que el suelo era todo tierra movediza se formaba con ella un espesísimo barro que hacía perder la tersidad a los piquetes, aflojándolos. Por efecto de las continuas lluvias se inundaba el Campamento, viéndose precisados los centinelas así como los cabos, sargentos y oficiales de servicio del recinto el cubrirse de barro hasta las rodillas.

Terminadas las lluvias se procedió a formar con piedras unas veredas por todo el recinto y por entre las tiendas para que en el caso de reanudarse las aguas estuviese al menos más libre el paso.

La fuerza, desde el primer día del establecimiento del Campamento, se dedicaba a los trabajos de fortificación, empleando en los referidos trabajos las horas siguientes: desde las siete y media de la mañana hasta las diez y por la tarde desde las tres hasta las seis.

El mes de octubre, en el primer día, se da parte al Sr. Comandante Jefe de estas fuerzas de que se tienen confidencias en el Campamento de que una partida de malhechores merodeaba por las inmediaciones del mismo, por lo cual el Comandante ordena que una sección al mando del $2^{\circ}$ Teniente, D. Francisco Planas de Tovar, haga un reconocimiento por dichos alrededores. Practicado éste resultó haberse observado huellas indelebles de recientes pisadas en una casa situada al frente de nuestro Campamento, siendo tiroteada la Sección por un grupo de moros: álgunos a caballo a una distancia de 200 metros, contestándoles la fuerza y haciéndoles huir a la desbandada. El Jefe de la Sección, por tener órdenes en contrario, desistió seguir avanzando en la persecución del enemigo (23), continuando después el citado día sin novedad dedicado exclusivamente a los trabajos de fortificación, consistente en una alambrada formada entre tres hileras de estacas de 10 centímetros de diámetro. Los alambres en su longitud van precedidos, de diez en diez centímetros, de unas rosetas con cuatro pinches

(23) Cfr. notas $\mathrm{n}^{\circ} 9,15$ y 20 . Hay que insistir que la forma de combatir de los indígenas eran totalmente antitética con respecto a los procedimientos que conocían los españoles: el principal problema estratégico, táctico y logístico era el que imponía la acción de un ejército convencional contra un enemigo aguerrido, conocedor del terreno, que lucha cerca de sus casas. Esto daba un carácter terriblemente desigual a la lucha, con grave desventaja para los españoles, ya que la concentración de sus tropas dispersaba a los moros sin vencerlos y la dispersión de los españoles (guerrillas contra guerrillas) les impedía la utilización de aquellos elementos convencionales en que tenían superioridad. 
-impedimenta para evitar el asalto; separadas dichas alambradas 15 metros del recinto, rodean todo el Campamento; también se construyen resguardos de tiradores a unos 200 metros de la fortaleza. Además, los soldados se dedican muchísimos días al desembarco de aprovisionamiento.

En el día 2, igualmente embebidos en nuestras faenas, se nos presentan 6 moros con banderas blancas y el día 3 , igualmente ocupados, fueron presentados al Campamento una caravana compuesta de 8 moros y 8 moras, otro tanto de chiquillos, tres toros y cuatro asnos cargados de enseres para comodidad de la vida de las mencionadas familias, pues así debía de ser puesto que venían divididos en grupos como de matrimonios. Fueron puestos a disposición del Sr. Comandante Jefe de nuestras fuerzas y conducidos después por dos parejas de riffeños de la policía exterior española.

Continúan los días sin novedad y siempre la fuerza franca de servicio dedicada en los trabajos de fortificación del Campamento. En los días que han transcurrido de este mes ha sido aumentada la policía con 20 hombres más.

El día 6 del mismo mes unos trompetazos tan desafinados como agudos nos anunciaban el pasado día mientras el sol dejaba libre el campo a la nueva luna de octubre: la llegada del Ramadán.

Al mismo tiempo que esto ocurría fuertes cañonazos disparados a bordo de un buque francés servía de acompañamiento, formando una orquesta verdaderamente original. Los cientos de personas que por aquella hora transcurrían por el centro de la población, se miraban asombradas sin poder comprender lo que aquella música signifícaba. Unos miraban a lo alto de las mezquitas de donde procedían los sonidos trompetiles, y otros, los menos confiados se dirigían al muelle con objeto de enterarse hacia que parte iban destinadas las bombas francesas, creyéndose ya en un nuevo y vigoroso ataque a la Plaza.

Los últimos se equivocaban. Los cañones de los barcos franceses no trataban de herir a ninguna kabila enemiga; por primera vez no hacían sangre: era todo lo contrario.

El Ramadán, que todos los años empieza con la luna de octubre, llegó y los franceses, sin duda, vinieron a recordar a los marroquíes sus obligaciones a cañonazos; lo tuvieron muy en cuenta y procuraron meter ruido por si no se oían las trompas morunas.

La antedicha orquesta, tan extraordinaria para nosotros, se repite todos los días a las 6 de la tarde y 3 de la madrugada durante el mes de abstinencia y es que en estas determinadas horas efectúan sus comidas. La alegre comida desaparece y se convierte en la lúgubre 
cena nocturna. A las tres de la madrugada se alimentaban para todo el día siguiente el cual dedicaban por completo a la oración. Tampoco fuman ni beben.

Los sonidos trompetiles suenan con un poder tan sobrenatural que en la primera noche sobrecogieron grandemente a todos nosotros, alucinándonos que se intentara entre ellos una gran acometida sobre la línea de combate para un intento de asalto a la Plaza. Los cañonazos del buque francés aumentaban más nuestro error: tal vez los tremendos trompetazos servían de aviso a los salvajes enemigos y se hallaran atacando algún campamento francés del flanco izquierdo y al cual se creía fuesen dirigidos los proyectiles de nuestros aliados.

De tal duda fuimos sacados por los riffeños, tiradores del Riff de Ceuta, que también estaban establecidos en una tienda en nuestro Campamento: que también aprovechaban el aviso de la tan extraordinaria orquesta para dar principio a su comida, pues hijos de la misma religión se contribuían también para cumplirla. Enterados, renació otra vez la tranquilidad, sirviéndole a nuestros centinelas en todos los demás días de abstinencia, de compañeros, los sonidos impertinentes de los desacompasados instrumentos.

El día 8, con motivo de la llegada al Campamento del Comandante del Primer Batallón de nuestro Regimiento, D. Julián Jorf García, con el carácter de Inspector de la fuerza, quedaron suspendidos los trabajos de fortificación para dedicarlos exclusivamente a la limpieza general del Campamento, así como aseo personal y equipo de soldado. A las 11, hora designada para la formación se encontraba en tal estado la fuerza, cuando apercibido el centinela de la entrada situada a la retaguardia de la presencia del mencionado Jefe dio su potente voz de: ¡Guardia formar! A esta voz, los soldados de dicha guardia al mando de un cabo, formaron en línea frente al enemigo y al pie de sus armas.

El Jefe Inspector pasó minuciosa revista a la fuerza y lugares del Campamento, quedando completamente satisfecho de la conservada disciplina del soldado. Al día siguiente ordenó que por el Maestro armero y en su presencia se efectuara la revista de armamento, quedando igualmente satisfecho.

El día 10, a las 4 de la tarde, se distribuye a la tropa el capote y $\operatorname{ros}(24)$.

(24) El ros es un cubrecabezas de fieltro con la parte superior y visera charoladas de negro. Debe' su nombre al general Ros de Olano, que lo declaró reglamentario en 1855 . 
En los demás días del mes en que nos ocupamos son anunciadas dos revistas más por el Sr. Comandante Subinspector, de las cuales la primera es en traje de paño, con capote, ros, fusil y correaje y la segunda de todas las prendas del soldado; esta última anunciada para el día 19, fue mal interrumpida por los cañonazos de los franceses. Poco después un soldado de la misma nacionalidad, según le ordenaban sus jefes, nos comunicaba en parte escrito que el enemigo se corría hacia el flanco derecho, lugar en el que se encontraba situado nuestro Campamento. Con tal motivo se suspendió la revista yendo cada uno a ocupar el lugar que se le tenía designado de antemano para la defensiva. Y en esta disposición estuvieron los soldados hasta oscurecido, hora en que el enemigo se había quitado ya del alcance de los proyectiles. Restablecida la tranquilidad se aplazó la revista hasta el día siguiente.

Al día siguiente, una vez que la tranquilidad era completa, se procedió a lo anunciado quedando el Sr. Subinspector igualmente satisfecho.

En los restantes días del mes la tranquilidad es completísima; los soldados dedicados a los trabajos de fortificación dan por terminada la alambrada que ha sido aumentada con otra hilera más de estacas, con tal motivo el cordón de centinelas queda reducido en 10 hombres durante la noche y 4 en el día. Los trabajos de fortificación siguen consistentes en trincheras próximas a la alambrada con comunicaciones al interior del Campamento. También se construyen garitas para los centinelas y los oficiales y se confeccionan locales para guarecerse bien de la impertinente estación del mes de diciembre que se aproxima.

Entramos en el mes de noviembre con la misma tranquilidad de los últimos días del pasado octubre. La fuerza franca de servicio continúa dedicada a los mismos trabajos, lo que muy en breve han de quedar terminados para encontrarse el Campamento casi en completo estado de seguridad.

Sigue su curso el mencionado mes presentándose siempre a nuestro Campamento, sin cesar, numerosos moros pacíficos que son presentados a la Autoridad Superior que ya tenemos mencionada anteriormente.

En los días 6 y 7 circulan rumores de que nuestras fuerzas serán relevadas en breve, una vez que la tranquilidad se ha ido normalizando, por lo cual nuestro Gobierno tiene a bien dar las oportunas órdenes para nuestro relevo, pues sólo son 300 soldados infantes y 100 de caballería los que sufren las penalidades de la campaña. Y dado los pequeños gastos que ocasiona el relevo del escaso número de hombres es de acuerdo 
que los Regimientos de guarnición en Ceuta: Serrallo 69 y Ceuta 60 contribuyan también a soportar los antedichos sufrimientos. El General de la Plaza de Ceuta D. José García Aldave, según instrucciones recibidas de su Gobierno da las órdenes oportunas para que la $1^{\mathrm{a}}$ y $2^{\mathrm{a}}$ Compañías del Primer Regimiento de Artillería Serrallo 69, preparadas convenientemente, sean embarcadas en el vapor "Ciudad de Cádiz" que con tal efecto había fondeado de nuevo en el puerto de Ceuta.

El día 9 fuimos sorprendidos por la magnífica presencia del trasatlántico. El día 10 se dedicó para los preparativos de marcha y el 11 fue embarcada nuestra $1^{\mathrm{a}}$ Compañía y poco después la $2^{\mathrm{a}}$, ocupando nuestro Campamento las dos compañías que ya fueron mencionadas.

En los semblantes de los soldados se ve expresado el sentimiento que les causa abandonar aquel lugar que tantas fatigas y trabajos ha costado en tan poco tiempo de estancia. Este lugar quedaba ya fortalecido de un modo extraordinario. De todas partes surgían magníficas trincheras que hubiesen resistido el avance del más fuerte ejército marroquí. Los nuevos ocupadores del Campamento habían de pasar vida más tranquila. ¡El estado del Campamento se lo permitía! ¡Dentro de aquella fortaleza cada hombre valía por ciento!

Con la resignación disciplinada del soldado español fueron reembarcados (25).

A la caballería también ha dado orden nuestro Gobierno, aunque sin sustitución, para que también sea reembarcada. Con tal motivo los soldados infantes se ven precisados a hacer vida marítima a bordo del mencionado buque fondeado en el puerto.

El día 13, una vez terminados estos trabajos, a las 8 de la tarde nuestro trasatlántico se mece orgulloso, como satisfechísimo de su preciosa carga, emprendiendo su salida.

Entre los soldados se oye de continuo los aires andaluces que cunden por los aires, buscando un refugio en el alma que ha dado el ser a aquellas bocas que sólo lanzan sentimientos nacidos del fondo de su corazón, alimentando la esperanza de curar las grandes fatigas en los brazos de sus padres y también, tal vez, en las de sus hermanos que esperan impacientes tan potentísima felicidad.

(25) Ló mismo que ocurrirá con las despedidas, esta actitud que leemos en el Diario cámbiará radicalmente en el soldado español. El militar de carrera verá atónito cómo la tropa, cada vez más, entrará en combate a regañadientes o desertará. Las estadísticas son elocuentes; la proporción de desertores entre los declarados aptos no hace más que aumentar: un 10,31 por ciento en 1909, un 18,92 por cierto en el 1912 , y en 1914 se alcanza un 22,09 por ciento. 
Llevamos dos horas de travesía cuando nuestro barco empieza a sufrir unas fuertes sacudidas que producen en sus conducidos un malestar grandísimo en sus cabezas. La navegación se nos presenta penosísima y tenemos que atravesar el Estrecho de Gibraltar (tumba marina) que con sus recuerdos debilita los ánimos de todos los navegantes.

Los soldados alimentan en su alma la esperanza de siempre soportar las penalidades alegremente. El mar sigue embraveciéndose y nuestro barco parece ser como que se ha convertido en un ser humano que todo lo sugestiona con su poder y sabiduría. Las soberbias olas amenazan con barrer toda la cubierta, pero nuestro barco también parece poseer un corazón sensible en el que hubiese causado sensaciones profundas los cánticos de los nuestros, según su supremo esfuerzo para combatirlas.

Han transcurrido 18 horas de navegación a las cuales se divisa el cabo Espartel (26) que nos avisa con sus blanquísimos muros que nos encontramos muy cerca de la población moruna de Tanger. Hemos llegado al mencionado puerto marroquí sin lamentar desgracia alguna. En él se encuentran también fondeados nuestros barcos guerreros Numancia y Extremadura y un potentísimo acorazado francés de seis chimeneas.

La popularísima población marroquí se presenta a nuestra vista muy silenciosa; no se nota ese murmullo que invade los muelles de mucho tráfico; parece como que esta población moruna guarda sus respetos a los barcos sitiadores.

Hemos fondeado para desembarcar al Comandante Sr. Santa Olalla, el cual ha de quedar en ella ignorándose cual sea su cometido a cerca de las instrucciones que haya recibido de nuestro Gobierno.

Sólo se notan los repetidos sonidos trompetiles, de simulación de combate, a bordo del invencible acorazado. Hemos terminado la misión en ella y nuestro buque vuelve a levar anclas y de nuevo se interna en los mares buscando la temeraria embocadura del estrecho.

Nuevamente nos vemos sorprendidos por el furor de las olas, las que son mayores a medida de nuestra internación y barren la cubierta con el mayor asombro de todos.

Algunos soldados, los menos resistentes de la vida marítima se tienen en el suelo fatigados y buscando apoyos donde hacerse fuertes del empuje de las corrientes. Hemos entrado en el Estrecho de Gibral-

(26) Es el antiguo Ampelusia promontorium. 
tar, ya se divisa la Plaza que habíamos abandonado para combatir a los enemigos y a la que muy pronto volveremos a pisar para relatar a nuestros compañeros detalles de nuestra ausencia.

El mar está enfurecido completamente. Sólo nos quedan 10 minutos para que nuestro conductor fondee en el puerto y aún todavía se duda de un término feliz.

Eran las seis y media de la tarde: nuestro buque se había puesto a cubierto de Sierra Bullones; al abrigo de éstas se quita de las embravecidas olas internándose con pausa en el puerto de Ceuta en el que fondea con el mayor contento de todos.

Al costado del trasatlántico se aproximan las barcazas para el desembarque. Los soldados se aglomeran para gozar del magnífico espectáculo y en sus semblantes se pinta una satisfacción inmensa.

Son desembarcados con sumo cuidado de los autores de tal misión y a su llegada al muelle son aclamadísimos y sostenidos en los brazos de sus más leales compañeros que los reciben orgullosos.

Se les han concedido unos minutos para que sean invertidos en tan gratísima tarea y después dan la orden para formar y marchar al Cuartel de la Reina, en el que les esperan y son obsequiados con cafés y licores dulces.

Volviendo después de algunos días de descanso a prestar el servicio de la guarnición de la Plaza.

José Cambiazo Botana 